\title{
The use of physical assessment skills by registered nurses in Australia: Issues for nursing education
}

\author{
Melanie Birks, PhD, MEd, BN, DipAppSci(Nsg), RN, FRCNA a,*, \\ Robyn Cant, PhD, MHIthSc, GradDipHEd ${ }^{\mathrm{b}}$, Ainsley James, MN, GradCert.HEd, \\ GradCert.Paeds, BN, RN c, Catherine Chung, MAdvNsgPrac (Emerg), Grad.Dip \\ AdvNsgPrac (Emerg), Grad.Cert HPE, BN, RN'c, Jenny Davis, Grad Dip Crit \\ Care, Grad Dip Periop, GradCert.HEd, BHIM (Hons), BAppSci (Nsg), Cert IV \\ T\&A, RN, RM, MRCNA ${ }^{d}$
}

\author{
a School of Nursing and Midwifery, Learning and Teaching Education Research Centre, Central Queensland University, Noosa \\ Campus, Queensland 4566, Australia \\ b School of Nursing and Midwifery, Monash University, Berwick, Victoria 3806, Australia \\ c School of Nursing and Midwifery, Monash University, Churchill, Victoria 3842, Australia \\ 'Central Queensland University, Noosa Campus, Queensland 4566, Australia
}

Received 14 December 2011; received in revised form 20 February 2012; accepted 21 February 2012

\section{KEYWORDS}

Health assessment; Nursing assessment; Physical assessment skills;

Undergraduate nursing education

\begin{abstract}
Summary The purpose of pre-service nursing education programs is to prepare competent graduates who are able to function as safe, professional registered nurses. An extensive element of these programs is the teaching of physical assessment skills, with most programs educating students to perform over 120 such skills. Previous research from North America suggests that the majority of skills taught to nurses in their pre-service programs are not used in practice. As part of a larger study, an online survey was used to explore use of 121 physical assessment skills by Australian nurses. Recruitment occurred via mailed invitation to members of the Australian Nursing Federation. Data were extracted from 1220 completed questionnaires returned by nurses who were mostly employed in New South Wales, were female and experienced nurses. Respondents indicated that they used only $34 \%$ of skills routinely. Results reinforce evidence found in the literature that many of the skills taught to nurses are either not used at all (35.5\%) or are used rarely (31\%). These findings have implications for the teaching of physical assessment skills in pre-service nursing programs, and raise questions about the value of extensive skills teaching in the context of contemporary health care. Further research into barriers to the use of physical assessment skills in nursing and the need for comprehensive skills preparation for the generalist nurse is likely to offer some solutions to these questions.

(c) 2012 Australian College of Nursing Ltd. Published by Elsevier Ltd.
\end{abstract}

* Corresponding author. Tel.: +61 754407034 .

E-mail address: m.birks@cqu.edu.au (M. Birks). 


\section{Introduction}

University programs aim to educate pre-registration nursing students to achieve competence in the skills required for the physical assessment of patients. Debate exists, however, about whether nurses are adequately prepared for practice (Berkow, Virkstis, Stewart, \& Conway, 2009). This is in spite of the fact that the average nursing curriculum requires pre-registration nursing students to master over 120 observational and assessment skills (Giddens, 2007). A recent survey of nurses in clinical practice in USA reported use of only half this number (Giddens \& Eddy, 2009). A degree of conflict therefore exists between what is taught and what is required for physical assessment of patients. This paper reports on a study that aimed to examine registered nurses' utilization of physical assessment skills in practice.

\section{Background}

The demands placed on newly qualified nurses by increasingly complex health systems, together with the explosion of knowledge and use of increasing technology, reinforce the need for skilled new graduates (Halfer \& Graf, 2006). Studies over the past decade suggest that graduates are not meeting competency expectations from the employer point of view, or are not 'practice ready' (Berkow, Virkstis, Stewart, \& Conway, 2009; Burns \& Poster, 2008). Concomitantly, various studies have described a mismatch between what is taught in pre-registration programs and the ability of new nurses to function in clinical situations (Lee et al., 2002; Maben, Latter, \& Clark, 2006). While universities constantly strive to develop competency-based curricula that will prepare new nurses for independent practice, few studies have evaluated the application of physical assessment skills learned during nursing education in the real-world environment of clinical practice.

In order to meet the requirements for registration, nurses are required to reach the level of proficiency prescribed by national competency standards for a registered nurse (Australian Nursing and Midwifery Council, 2006). Physical assessment in this context is a part of health assessment; it includes a sequence of data collection using inspection, palpation, percussion and auscultation (employing nurses' core senses of sight, hearing, smell and touch) (Baid, 2006). Nurses then interpret clinical findings in the context of the patient's history. Secrest, Norwood, and DuMont (2005) suggest that all nurses must be able to detect alterations in the status of their patients to provide the appropriate nursing care. In most Australian universities, nursing education during undergraduate years involves teaching students an extensive number of different skills for assessing the physical status of a patient. Based on standard nursing texts, 120 skills have been identified as being demanded of students (Giddens, 2007; Wilson \& Giddens, 2000). In contexts where this number is in fact taught, actual mastery of all these skills may not be possible. In a small study that surveyed faculty members and 51 clinical nurses in the USA, respondents reported that nearly all of 120 physical assessment skills were taught in the baccalaureate nursing program, although only $29 \%$ of skills were regularly performed (daily/weekly) in clinical practice (Secrest, Norwood, \& Dumont, 2005). A subsequent study of 193 nurses reported that nurses routinely used only 30 skills, prompting the author to question whether the teaching of assessment skills to such an extent was in fact necessary (Giddens, 2007). No recent published data on Australian general nurses' physical assessment practices has been identified.

The research reported in this paper was undertaken as part of a larger study that aimed to examine the relevance of physical assessment skills taught in pre-registration nursing programs. As the second part of a two-phase study, the survey reported on here aims to identify the use of physical assessment skills by registered nurses working in clinical environments. The survey tool was based on one developed by Giddens (2007) in her work with nurses in the USA.

\section{Methods}

Quantitative survey by questionnaire was chosen as the most efficient and effective method for obtaining data from a broad sample of nurses practicing in Australia. Following approval from the university's ethics committee, a convenience sample of registered nurses was recruited with assistance from the Australian Nursing Federation (ANF). The ANF advertized an invitation to participate with a survey access link in their professional journal. Owing to the limited response, recruitment was subsequently extended and individualized invitations were generated. The ANF (NSW) sent an individual e-mailed survey invitation and access link to a random sample of their members who were registered nurses. The surveys were conducted between October 2010 and July 2011.

The survey instrument developed by Giddens (2007) was modified to ensure relevance to the Australian environment. This modification included changing some terminology in respect of items that sought demographic data: postal code, practice status, age, sex, qualifications, work role and length of nursing experience. The questionnaire is divided into skills sections based on human anatomical and physiological functional or regional group: integument, nutrition, head, ears/eyes, neck/thorax, breasts/spine, cardiovascular, musculoskeletal, abdomen/anus, reproductive, neurological and sensory. In total there are 121 items. Respondents were asked to indicate their use of skills in accordance with frequency of practice based on a six-point Likert scale (Table 1). The survey was pre-tested electronically on-line by a panel of six university nursing lecturers. No changes were deemed necessary following this process and the survey was subsequently posted on-line for participants to complete.

Data were downloaded and analyzed using SPSS statistics software (SPSS Inc., 2007). Summary statistics (means, percentages) were used to describe demographic variables. Spearman's rank order correlation was used to determine association between demographic variables. For each of the scale items the median response was computed from the response range $(0-5)$ and this was used as the main indicator of overall skills use. Section ratings were summed by category of survey item (e.g. 'Head', 'Neck, Thorax') to obtain a sectional response score. Differences by professional role were explored using these grouped data with Wilcoxon signed ranks test (as an alternative to $t$-tests owing 
Table 1 Frequency of practice response scale.

\begin{tabular}{|c|c|}
\hline Coding scale & Response definition \\
\hline 0 & I do not know how to do this technique. \\
\hline 1 & $\begin{array}{l}\text { I know how to do this technique, but } \\
\text { have never done this in my clinical } \\
\text { practice. }\end{array}$ \\
\hline 2 & $\begin{array}{l}\text { I perform this technique rarely (a few } \\
\text { times in during my career). }\end{array}$ \\
\hline 3 & $\begin{array}{l}\text { I perform this technique occasionally (a } \\
\text { few times a year). }\end{array}$ \\
\hline 4 & $\begin{array}{l}\text { I perform this technique frequently in } \\
\text { my clinical practice (every } 2-5 \text { times I } \\
\text { work). }\end{array}$ \\
\hline 5 & $\begin{array}{l}\text { I perform this technique regularly in my } \\
\text { clinical practice (every time I work). }\end{array}$ \\
\hline
\end{tabular}

to the non-normality and skewed responses), with $p \leq 0.05$ regarded as significant for all tests. The survey was found reliable with a Cronbach alpha statistic of 0.989 for the 121 items.

\section{Results}

Of a total of 1518 returned surveys, 1220 were deemed to be completed and were therefore subjected to analysis. Since the initial survey population was unknown, a response rated could not be ascertained.

\section{Demography}

All participants were Registered Nurses, with 69 reporting they were Registered Midwives. Nine of every ten were currently practicing nurses working in a clinical setting ( $n=1119,92 \%)$. The most common nursing role was 'registered nurse' (520; 43\%). Others were: clinical specialist, educator or consultant $(323,26.7 \%)$; nurse manager or administrator $(168,14 \%)$; midwife $(69,5.7 \%)$; community nurse $(48,4 \%)$; mental health nurse $(31,2.6 \%)$; researcher or teacher $(22,1.8 \%)$. Nearly all nurses $(97 \%)$ worked in the state of New South Wales (NSW) according to their recorded postcode. The remainder were employed in Victoria, South Australia and Tasmania.

Most respondents were female $(1081 ; 88.6 \%)$ and were mature aged with the most common age range being $51-60$ years $(n=409,33.6 \%$, range $21-60+)$. The majority worked full time $(n=735,60.5 \%)$. Most were experienced nurses; half with 20 or more years of clinical practice as shown in Fig. 1. Ninety percent reported they held a bachelor degree or equivalent nursing qualification, with $10 \%$ qualified at masters or doctoral level.

\section{Functional groups and regions surveyed}

Skills for assessing 12 body functional groups and regions were surveyed, involving skills for inspection, palpation, percussion and auscultation. Possible median responses on the 121 skills ranged from 0 to 5 . No skills received a median

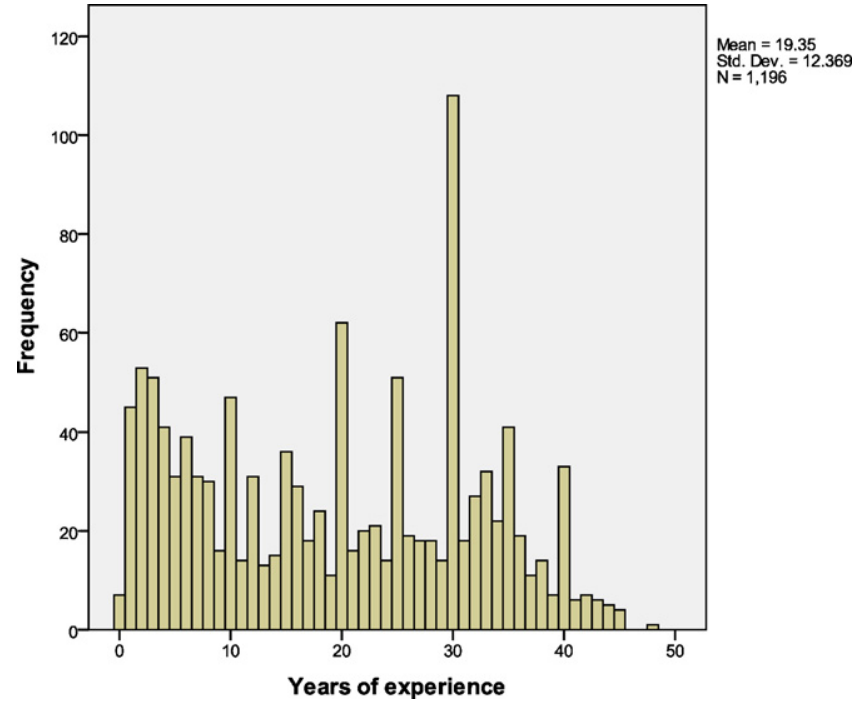

Figure 1 Years of experience working as a registered nurse.

rating of ' 0 ', indicating that all skills were viewed by nurses as having been taught.

As shown in Fig. 2, there were 43 skills (35.5\%) identified with a median response rate of 1 (techniques learnt but never performed). There were 37 skills $(31 \%)$ with a median score of 2 (techniques used rarely). There were 28 skills (23\%) with a median score of 3 and 4 (techniques used frequently or occasionally). The remaining 13 skills $(11 \%)$ had a median score of 5 , indicating the techniques were used 'every time I work'. Table 2 ranks skills use for the whole sample, grouped by median response. These results suggest that most of the 121 skills had been taught to nurses but many were never performed in practice.

\section{Influence of nursing roles}

Although median scores provide a snapshot of overall assessment skill use, this broad measure does not account for practice variations imposed by the clinical specialty of

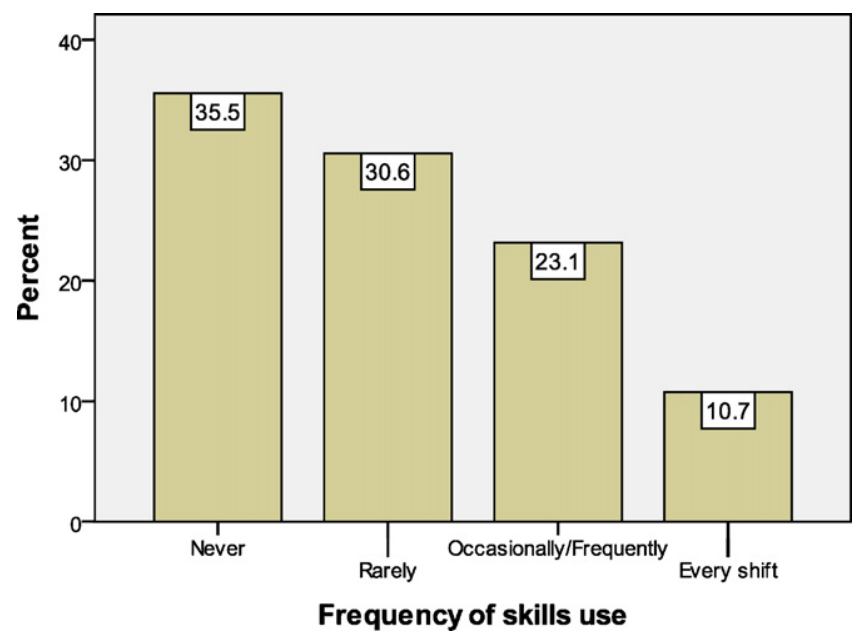

Figure 2 Frequency of physical assessment skills used by nurses based on the median score $(N=1220)$. 
Table 2 Ranking of physical assessment techniques used in clinical nursing practice based on the median response $(\mathrm{N}=1220)$.

\begin{tabular}{|c|c|c|}
\hline $\begin{array}{l}\text { Used every time I work } \\
\quad(\text { median response }=5)\end{array}$ & $\begin{array}{l}\text { Used frequently or occasionally (median } \\
\text { response }=3 \text { or } 4 \text { ) }\end{array}$ & Used rarely $($ median response $=2$ ) \\
\hline $\begin{array}{l}\text { Inspect overall skin } \\
\text { colour/tone } \\
\text { Inspect skin lesions } \\
\text { Inspect wounds } \\
\text { Evaluate breathing effort } \\
\text { (rate, patterns, chest } \\
\text { expansion) } \\
\text { Assess mental status/level of } \\
\text { consciousness } \\
\text { Glasgow Coma Scale } \\
\text { Evaluate speech } \\
\text { Palpate distal pulses for } \\
\text { circulation } \\
\text { Palpate and inspect capillary } \\
\text { refill } \\
\text { Inspect/palpate extremities } \\
\text { for oedema } \\
\text { Palpate extremities for } \\
\text { temperature } \\
\text { Inspect extremities for skin } \\
\text { colour/hair growth } \\
\text { Inspect abdomen }\end{array}$ & $\begin{array}{l}\text { Assess BMI through measurement of } \\
\text { height and weight } \\
\text { Inspect oral cavity } \\
\text { Inspect/palpate external ear } \\
\text { Assess hearing based on conversation } \\
\text { Assess hearing using whisper and/or } \\
\text { finger rubbing test } \\
\text { Inspect external eyes } \\
\text { Assess visual acuity } \\
\text { Inspect/palpate external ear } \\
\text { Inspect chest shape } \\
\text { Palpate chest wall for thoracic expansion } \\
\text { Percuss the lungs } \\
\text { Auscultate lung sounds } \\
\text { Inspection of female genitalia (hair } \\
\text { distribution, vulva) } \\
\text { Inspection of male genitalia (pubic hair, } \\
\text { penis, scrotum) } \\
\text { Inspection of groin area } \\
\text { Assess facial movement and symmetry } \\
\text { (raise eyebrows, wrinkle forehead, show } \\
\text { teeth, puff out cheeks) } \\
\text { Test for gag reflex } \\
\text { Assess gait } \\
\text { Sensation to light touch } \\
\text { Sharp/dull sensation } \\
\text { Inspect the breasts } \\
\text { Inspect for jugular pulsation } \\
\text { Inspect muscles and extremities for } \\
\text { size/symmetry } \\
\text { Palpate extremities for tenderness } \\
\text { Palpate joints for tenderness } \\
\text { Observe range of motion of joints } \\
\text { Measure range of motion of joints with } \\
\text { goniometer } \\
\text { Assess for carpel tunnel using Phalen's } \\
\text { sign or Tinel's sign } \\
\text { Auscultate abdomen for bowel sounds } \\
\text { Palpate abdomen for generalized } \\
\text { tenderness, distension }\end{array}$ & $\begin{array}{l}\text { Inspect hair for colour, texture } \\
\text { Inspect internal nasal cavity with light } \\
\text { source } \\
\text { Palpate lips, tongue, mucous } \\
\text { membranes of mouth } \\
\text { Inspect the internal ear with an otoscope } \\
\text { Assess hearing using whisper and/or } \\
\text { finger rubbing test } \\
\text { Assess peripheral vision } \\
\text { Inspect corneal light reflex } \\
\text { Check PERRLA } \\
\text { Palpate thyroid gland } \\
\text { Palpate the trachea } \\
\text { Palpate lymph nodes in the neck } \\
\text { Palpate chest wall for vocal fremitus } \\
\text { Percuss for diaphragmatic excursion } \\
\text { Auscultate the chest for vocal reso } \\
\text { Palpation of female genitalia } \\
\text { Palpation of male genitalia (penis, } \\
\text { scrotum) } \\
\text { Palpation for hernia } \\
\text { Evaluate olfactory nerve (smell test) } \\
\text { Test tongue for taste } \\
\text { Test shoulders for muscle strength } \\
\text { Assess patient ability to hop on one foot } \\
\text { Assess patient ability to walk on } \\
\text { heels/then toes } \\
\text { Assess fine motor coordination } \\
\text { (finger/thumb; nose/index finger) } \\
\text { Vibratory sensation } \\
\text { Position sense } \\
\text { Perform a clinical breast examination } \\
\text { Inspect the spine } \\
\text { Palpate the spine } \\
\text { Pssess range of motion to back/spine } \\
\text { Auscultate thorax for heart sounds } \\
\text { Auscultate carotid artery } \\
\text { Estimate (measure) jugular venous } \\
\text { pressure } \\
\text { Auscultate abdomen for vascular sounds } \\
\text { Percuss abdomen for abdominal tones } \\
\text { Palpate to determine liver span } \\
\text { Pssess for a mass } \\
\text { Paten }\end{array}$ \\
\hline
\end{tabular}

nurses' work. Median scores of 1 or 2 (performed never or rarely) suggest these skills are not performed by the entire sample group, while median scores of 3 or 4 suggest wider use. It is apparent that the use of skills was influenced by the nursing role. For example, of five cardiovascular assessment skills with an overall median score of 5 that were commonly performed 'every time I work', the mental health nurse subgroup assessed these less frequently as their median score was 3 or 4 (performed frequently/occasionally). As expected, the midwife subgroup had significantly higher scores on frequency of reproductive health assessment skills $(n=61$; mean: $51.7 \pm 10.06)$ compared with all nurses (mean: $28.69 \pm 12.61, p \leq 0.001$ ). Almost all midwives (94\%) palpate the uterus in pregnancy to measure fundal height and $93 \%$ palpate the foetal position. Alternatively, only $6 \%$ of midwives frequently palpate for a hernia or $3 \%$ for a prostate. While these results confirm the currency of practice variations, a more detailed analysis is beyond the scope of this paper. 


\section{Assessment practices}

On completion of the survey, respondents were given an opportunity to make further comments. Two of every three respondents provided general comments, while even more listed specific skills they used that could have been included in the survey. A commonly occurring theme was that nurses offered suggestions as to why specific skills were not used in the practice setting. These factors are explored below, with illustrative quotations from the nurses.

The results of the survey indicate that 43 skills (36\%) commonly taught in pre-registration nursing programs are not actually performed. Some nurses reported that in their current field of practice a number of skills were taught but not performed because they were not required in that particular clinical environment.

"Like many nurses, I have learnt majority of these assessments, but due to the areas I have worked in over the years and currently, majority of these assessments are not required as they are very specific assessments."

Some nurses even reported that they believe they have lost the ability to perform certain physical assessment skills due to lack of opportunity and increased administrative requirements such as paper work.

"You are taught many skills at university but you never get to use them in nursing practice. It is all paper work and minimal patient care,'.

Even though some of these skills are not practiced in the clinical environment, one nurse suggested that knowing the theoretical knowledge behind the skill has been useful in her practice.

"I know very well but have never used at the bed side! However, this knowledge has been useful when interpreting doctor's notes, observations and recommendations regarding patient care.",

Responses showed that 37 skills were used 'rarely' and 28 skills used 'frequently or occasionally'. Variations in frequency of use may relate to individual work schedules and also to nurses' area of clinical allocation.

"I work on night shift so the assessments would be rare and... the area you are working frequently determines what assessment you will perform.",

"The assessment skills I do use regularly I learned in the clinical setting in the specialized area of haemodialysis".

The results show that few skills $(13 ; 11 \%)$ have a median score of 5; that is, few skills were routinely used on every shift. Commonly, the clinical speciality in which nurses were practicing was identified as a reason why certain physical assessment skills were or were not practiced.

"I work in an intensive care unit so we do thorough physical assessments at least once a shift. There are some skills I have no idea on how to do but would like to."

Overall, the main reasons why certain skills were not practiced were based on a lack of time or else specialty nursing roles that had a bearing on required skill sets.
Furthermore, there were numerous comments questioning whether certain physical assessment skills fell within a nurse' role or scope of practice, as nurses felt that those skills were in the domain of other health professionals such as doctors or allied health professionals.

"So many of the skills taught at uni are things that doctors do, not nurses. Maybe they are used by nurses in ICU settings?"'

"Many of the skills learnt during university training are redundant in a hospital setting, there is simply no time to use them. They also become primarily 'doctors domain' in hospital.",

It is clear from the comments above that the use of assessment skills in practice is heavily dependent on the clinical context.

\section{Discussion}

The results of this study indicate that a small number of physical assessment skills are regularly practiced in the clinical environment. The majority of the skills practiced 'frequently or occasionally' (18 out of 28), and 'every time I work' (9 out of 13) by registered nurses involved inspection and general observation of a patient. These results are consistent with research conducted by Giddens (2007) who identified a set of 30 physical assessment skills that were practiced by RNs in the USA, the majority of which employed inspection. There were, however, another 43 skills that nurses indicated had been taught-yet the current results show these were not practiced universally. This raises questions that should be debated, such as whether or not there is value in teaching skills that are not used in practice. In her work that was the impetus for this study, Giddens (2007) suggested that the teaching of this number of skills was, in fact, redundant given that they were not being performed.

The authors of the present study question this assertion, particularly when factors that impact on whether or not certain skills are performed are considered. The findings presented here suggest that the necessity or value of the skill appears to have little bearing on the incidence or frequency of use. Rather, issues such as time available to conduct physical assessments, area of clinical practice or specialty and the presence or absence of other health care professionals such as doctors and allied health professionals appear to be more influential.

\section{Barriers to conducting physical assessments}

The qualitative data gathered in this study indicates that time is a key factor that determines not only the type of physical assessment skills practiced by nurses, but also the depth of assessment they complete. For example, in a busy ward or department, a nurse may not have the time to perform a thorough respiratory assessment and may only complete inspection of factors such as a patient's respiratory rate, depth, effort, accessory muscle use. The nurse may omit palpation, percussion and auscultation knowing that the medical team will also be conducting a respiratory assessment as part of their role. This fits with the idea that there are two possible outcomes of nurses' physical 
assessment: the recognition of abnormality in a patient, and identification of a differential diagnosis (Baid, 2006). The current results support the use of the first of these and the notion that time factors are a barrier to nurses' depth of assessment. The results of our study concur with others; Skillen, Anderson, and Knight (2001) identified time as a necessary resource for conducting physical assessments in practice, and this was also suggested as a cause of the deficiency in the depth of assessments performed by RNs (Giddens, 2007).

It is well recognized that there can be a blurring of roles between doctors and nurses with the advancement of nursing and nursing specialties (Price, Han, \& Rutherford, 2000). Whose responsibility is it, then, to conduct physical assessment? In the past, physical assessment was commonly recognized as being part of the medical model of healthcare, however, the increasing incidence of acute and chronic illness suggests a need for nurses to develop their role to be more vigilant and systematic in their patient assessments (West, 2006). Results indicate that many nurses in the current study were unclear about whose scope of practice certain aspects of physical assessment fell within. Fennessey and Wittmann-Price (2011) suggest that physical assessment is a skill shared between nurses, medical personal and other health care professionals, with all members having the ability, skills and knowledge to conduct physical assessments when required. But whose role is it to conduct, for example, a respiratory assessment on a patient with an acute exacerbation of their respiratory condition? Is it the doctor who needs to gather information to make an accurate medical diagnosis; is it the nurse who needs to identify actual or potential problems in order to plan and implement interventions of a holistic nature; or is it the physiotherapist's role as they assess the patient before and after any supportive treatments or exercises? The boundaries of professional responsibility for physical assessment may thus be unclear. A recent study by Edmunds, Ward and Carnes (2010) that explored what physical assessment skills are being used found that that role boundaries and role specifications were lacking, allowing differing views on who should undertake physical assessment skills and under what circumstances. Other authors suggest the best patient outcomes result when all members of the health care team play a role in physical assessment (with each having their own goals) and work collaboratively to share their different goals and their findings (Fennessey \& Wittmann-Price, 2011).

The specialty area in which a nurse works also appears to influence the skills practiced. The exemplars from the participants indicate that a nurse's specialty (i.e. respiratory, cardiac, ICU, midwifery) often dictates the skills utilized (or not) in practice. This has consistently been reported in the literature (Edmunds, Ward, \& Barnes, 2010; Price, Han, \& Rutherford, 2000; Scott \& Maclnnes, 2006). For example, some participant nurses reported that when working in a rural or remote primary health care setting, they were able to practice a wider variety of skills. However, when transferring to other areas of clinical practice that were serviced by other health professionals such as doctors or allied health practitioners, some skills were then left up to those professionals to perform. Some nurses felt that some skills were actually in the doctors 'domain' or area of responsibility. It appears that roles and responsibilities were not clearly defined. However, there may be more clarity in nursing specializations such as in intensive care-where nurses reported that they conduct daily detailed physical assessments. Alternatively, there may be a need for skills development for nurses to more confidently conduct physical assessments-as several nurses in the current study stated they would like to learn more, and the time interval since participants' initial nursing education was lengthy. It is here that the importance of clinical role models comes into play. If a professional culture exists in which nurses are discouraged from working to their full scope of practice, skills atrophy is likely to result.

While the management of patients is becoming more complex (West, 2006), the need for nursing roles and scope of practice to evolve is clearly evident. Nurses are required to maintain skills to conduct regular physical assessments on their patients as a means of identifying changes in condition, whether a deterioration or improvement. The findings of this study suggest that the collateral value of skills teaching and the theoretical knowledge that underpins it is inherently valuable in itself.

\section{Implications for nursing education}

These results suggest that there is a need to identify what constitutes core, or essential, physical assessment skills relevant to current general nursing practice. This information would in turn inform the content and delivery of preregistration nursing programs. Should there be a diminution of the assessment skills curricula? This shift would enable a greater emphasis to be placed on teaching and the practicing of core skills to allow students to become competent and confident in performing a thorough physical assessment on their patients. Should those skills identified in this study as being redundant for most nurses be reserved for specialty nursing areas, where it is evident that specific education is required to supplement prior learning? Doing so would allow core skills to be the main focus of pre-registration courses, thus freeing up valuable time in an already crowded curriculum. Alternatively, should nurses in all areas of practice be expected to possess baseline competency in all physical assessment skills to ensure preparation for any and all potential areas of employment? Future research that explores in greater depth the factors that influence use of physical assessment skills by nurses, and also the need for a broad skills set in various areas of practice, would go some way to providing answers to these questions.

\section{Study limitations}

Some limitations apply to the conduct of this study. The sample of nurses recruited mainly from one state may not be representative of all Australian nurses. Self-reported data may be subject to bias, as nurses with most interest in the topic may have responded. The study replicated an earlier design and questionnaire, however, the use of median response data to represent the practices of nurses is an applied statistic that has limitations. Nevertheless, the large size of the sample $(N=1220)$ allowed a broad number of nursing roles to be surveyed and thus the findings will add to what little is already known about physical assessment skills use by Australian nurses. 


\section{Conclusion}

For the registered nurses who responded to this study, time pressures and role boundaries were barriers to conducting detailed physical assessments, while specialty roles appear to facilitate use of particular assessment skills. The results suggest that registered nurses are not utilizing a considerable proportion of the physical assessment skills that are currently being taught to undergraduate nursing students within their curriculum. Pre-registration nursing programs aim to teach skills, knowledge and attributes that reflect the contemporary Australian health care context. Should these programs be modified in acknowledgement of the subsequent disuse of these skills? Or should the health care environment embrace the broad scope of practice for which registered nurses are prepared? These questions highlight the need for the conduct of further research to explore barriers to the use of physical assessment skills by nurses and to identify strategies that might promote their use in practice. As assessment is the foundation of effective nursing care, improved patient outcomes may result from any strategy that enhances such activity.

\section{Acknowledgement}

The authors wish to acknowledge the support of the Australian Nursing Federation in providing a small grant to assist with the conduct of this research.

\section{References}

Australian Nursing and Midwifery Council. (2006). Australian nursing and midwifery council competency standards for the registered nurse (4th ed.). Dickson, ACT: Australian Nursing and Midwifery Council.

Baid, H. (2006). The process of conducting a physical assessment: A nursing perspective. British Journal of Nursing, 15(13), 710-714.

Berkow, S., Virkstis, K., Stewart, J., \& Conway, L. (2009). Assessing new graduate nurse performance. Nurse Educator, 34(1), 17-22, doi:10.1097/1001.NNE.0000343405.0000390362.0000343415.
Burns, P., \& Poster, E. (2008). Competency development in new registered nurse graduates: Closing the gap between education and practice. Journal of Continuing Education in Nursing, 39(2), 67-73.

Edmunds, L., Ward, S., \& Barnes, L. (2010). The use of advanced physical assessment skills by cardiac nurses. British Journal of Nursing, 19(5), 282-287.

Fennessey, A., \& Wittmann-Price, R. (2011). Physical assessment: A continuing need for clarification. Nursing Forum, 46(1), 45-50.

Giddens, J. (2007). A survey of physical assessment techniques performed by RNs: Lessons for nursing education. Journal of Nursing Education, 46(2), 83-87.

Giddens, J., \& Eddy, L. (2009). A survey of physical examination skills taught in undergraduate nursing programs: Are we teaching too much? Journal of Nursing Education, 48(1), 24-29.

Halfer, D., \& Graf, E. (2006). Graduate nurse perceptions of the work experience. Nursing Economics, 24(3), $150-155$.

Lee, Y., Chen, C. H., \& Wang, C. J. (2002). Entry-level skill competency: A comparison of head nurses expectations and new graduates perceptions. Journal of Nursing Research, 10(3), 217-226.

Maben, J., Latter, S., \& Clark, J. M. (2006). The theory-practice gap: Impact of professional-bureaucratic work conflict on newly-qualified nurses. Journal of Advanced Nursing, 55(4), 465-477.

Price, C., Han, S., \& Rutherford, I. (2000). Advanced nursing practice: An introduction to physical assessment. British Journal of Nursing, 9(22), 2292-2296.

Scott, C., \& Maclnnes, J. D. (2006). Cardiac patient assessment: Putting the patient first. British Journal of Nursing, 15(9), 502-508.

Secrest, J., Norwood, B., \& Dumont, P. (2005). Physical assessment skills: A descriptive study of what is taught and what is practiced. Journal of Professional Nursing, 21(2), 114-118.

Skillen, D., Anderson, M., \& Knight, C. (2001). The created environment for physical assessment by case managers. Western Journal of Nursing Research, 23(1), 72-89.

SPSS, Inc. (2007). Statistical Package for Social Sciences: Version 15. Chicago, IL: SPSS, Inc.

West, S. L. (2006). Physical assessment: Whose role is it anyway? Nursing in Critical Care, 11(4), 161-167. doi:10.1111/j.13621017.2006.00161.x

Wilson, S. F., \& Giddens, J. F. (2000). Health assessment for nursing practice (2nd ed.). St. Louis: Mosby. 